\title{
Laws, regulations, guidelines, and principles pertaining to laboratory animals in
} Southeast Asia

\begin{abstract}
Southeast Asia is a subregion of Asia, consisting of the following countries: Brunei or the Nation of Brunei; Cambodia or the Kingdom of Cambodia; Christmas Island (a territory of Australia); Indonesia or the Republic of Indonesia; Laos or the Lao People's Democratic Republic; Malaysia; Myanmar; Philippines or the Republic of the Philippines; Singapore or the Republic of Singapore; East Timor or Timor-Leste or the Democratic Republic of TimorLeste; Thailand or the Kingdom of Thailand; and Vietnam or the Socialist Republic of Vietnam. All these countries are members of the World Organisation for Animal Health (OIE). The OIE Terrestrial Animal Health Code (the Terrestrial Code) sets out standards for the improvement of animal health and welfare and veterinary public health worldwide, including standards for safe international trade in terrestrial animals (mammals, birds, and bees) and their products. This is achieved through the detailing of animal health measures to be used by the veterinary authorities of importing and exporting countries to avoid the transfer of agents pathogenic for animals or humans, while avoiding unjustified trade barriers. The Terrestrial Code is a reference document for use by veterinary authorities, import/export services, epidemiologists and all those involved in international trade. Section 7 of the Terrestrial Code covers animal welfare and Chapter 7.1 is called, "Introduction to the Recommendations for Animal Welfare." There is no specific overarching legislation applied for animal welfare relevant directly to laboratory animals for research, testing, and teaching in Southeast Asia. This chapter describes current laws, regulations, guidelines, and principles pertaining to laboratory animals used for research, teaching, and testing in some countries of Southeast Asia region including Cambodia, Indonesia, Philippines, Thailand and Singapore
\end{abstract}

Keyword: Animal welfare; Cambodia; Guideline; Indonesia; Laboratory animal; Law; Malaysia; Philippines; Principle; Regulation; Research; Singapore; Teaching; Testing; Thailand 